\title{
Numerical analysis of the primary processes controlling oxygen dynamics on the Louisiana shelf
}

\author{
L. Yu ${ }^{1}$, K. Fennel ${ }^{1}$, A. Laurent ${ }^{1}$, M. C. Murrell ${ }^{2}$, and J. C. Lehrter ${ }^{2}$ \\ ${ }^{1}$ Department of Oceanography, Dalhousie University, Halifax, Nova Scotia, Canada \\ ${ }^{2}$ US Environmental Protection Agency, Gulf Ecology Division, 1 Sabine Island Dr., Gulf Breeze, FL 32561, USA \\ Correspondence to: L. Yu (liuqian.yu@dal.ca)
}

Received: 3 September 2014 - Published in Biogeosciences Discuss.: 22 October 2014

Revised: 30 January 2015 - Accepted: 9 March 2015 - Published: 2 April 2015

\begin{abstract}
The Louisiana shelf, in the northern Gulf of Mexico, receives large amounts of freshwater and nutrients from the Mississippi-Atchafalaya river system. These river inputs contribute to widespread bottom-water hypoxia every summer. In this study, we use a physical-biogeochemical model that explicitly simulates oxygen sources and sinks on the Louisiana shelf to identify the key mechanisms controlling hypoxia development. First, we validate the model simulation against observed dissolved oxygen concentrations, primary production, water column respiration, and sediment oxygen consumption. In the model simulation, heterotrophy is prevalent in shelf waters throughout the year, except near the mouths of the Mississippi and Atchafalaya rivers, where primary production exceeds respiratory oxygen consumption during June and July. During this time, efflux of oxygen to the atmosphere, driven by photosynthesis and surface warming, becomes a significant oxygen sink. A substantial fraction of primary production occurs below the pycnocline in summer. We investigate whether this primary production below the pycnocline is mitigating the development of hypoxic conditions with the help of a sensitivity experiment where we disable biological processes in the water column (i.e., primary production and water column respiration). With this experiment we show that below-pycnocline primary production reduces the spatial extent of hypoxic bottom waters only slightly. Our results suggest that the combination of physical processes (advection and vertical diffusion) and sediment oxygen consumption largely determine the spatial extent and dynamics of hypoxia on the Louisiana shelf.
\end{abstract}

\section{Introduction}

The Louisiana shelf (LA shelf), in the northern Gulf of Mexico, receives large inputs of freshwater, nutrients, and organic matter from the Mississippi-Atchafalaya river system and experiences widespread hypoxia (oxygen concentrations $<2 \mathrm{mg} \mathrm{L}^{-1}$, or $62.5 \mathrm{mmol} \mathrm{m}^{-3}$ ) in bottom waters every summer (Rabalais et al. 2007; Bianchi et al., 2010). The classic paradigm for explaining the recurring hypoxic conditions on the LA shelf is that high nutrient inputs from the river stimulate high rates of primary production in coastal waters; as this organic matter sinks below the pycnocline and is respired, dissolved oxygen (DO) becomes depleted due to a combination of high microbial respiration and low reoxygenation of the bottom waters because of strong stratification (Rabalais et al., 2002).

While the statistical linkage between spring nutrient loads and the spatial extent of the summer hypoxic area is well documented (Turner et al., 2005; Greene et al., 2009; Forrest et al., 2011), the distribution of hypoxia on the LA shelf is known to be the integrated result of various physical and biogeochemical processes that interact nonlinearly (Bianchi et al., 2010; Fennel et al., 2011). Rowe and Chapman (2002) suggested that as the distance from the river mouth increases, the primary driver of hypoxia changes from deposition of riverine organic matter to biological production and respiration and finally to physical stratification. Model simulations (Bierman et al., 1994; Breed et al., 2004; Eldridge and Roelke, 2010) also show that the dominant processes contributing to hypoxia change in a westward direction; that is, allochthonous organic matter accounts for most of DO consumption near the Mississippi River mouth and au- 
tochthonous organic matter dominates DO consumption farther west. Hetland and DiMarco (2008) suggested that the differences in vertical stratification within the Mississippi and Atchafalaya River plumes lead to differences in the dominant type of respiration responsible for hypoxia, with water column respiration driving hypoxia near the Mississippi River plume and benthic respiration controlling hypoxia near Atchafalaya Bay and further west. Recent work suggests that the main axis of variability in hydrography and metabolism is inshore to offshore on the shelf (Lehrter et al., 2012, 2013; Murrell et al., 2013a; Fry et al., 2015).

Understanding the occurrence of hypoxia on the LA shelf requires quantitative knowledge of the mechanisms controlling DO dynamics. Generally, the distribution of DO is determined by physical processes (air-sea flux, horizontal advection, vertical mixing across the pycnocline) and biogeochemical processes (photosynthetic production, respiration in the water column and sediments, and oxidation of reduced substances) (Testa and Kemp, 2011). The magnitudes and spatial and temporal dynamics of these processes on the LA shelf are as of now poorly constrained.

Circulation over the LA shelf displays two distinct modes (Cochrane and Kelly, 1986; Cho et al., 1998): an upcoast circulation mode during the dominantly upwelling-favorable (westerly) winds in summer (June to August) versus westward flow during the dominantly downwelling-favorable (easterly) winds for the rest of the year. Previous statistical studies (Forrest et al., 2011; Feng et al., 2012) have shown that the observed hypoxic extent is correlated with the duration of upwelling-favorable wind. Feng et al. (2014) further showed that the wind influences the distribution of lowsalinity, high-chlorophyll water on the shelf and thereby the bottom-water DO concentrations and hypoxic area.

A substantial fraction of phytoplankton production is observed below the pycnocline (Lehrter et al., 2009) and even at the sediment-water interface when light is available (Lehrter et al., 2014), but the effect of sub-pycnocline production on bottom-water hypoxia is not well known. Eldridge and Morse (2008) highlighted the importance of benthic respiration as a DO sink at the beginning and end of hypoxic events, and suggested water column respiration in bottom water near the pycnocline as the primary oxygen sink once hypoxia has developed. Quinones-Rivera et al. $(2007,2010)$ estimated benthic respiration to account for $\sim 73 \%$ of the total DO loss within $1 \mathrm{~m}$ of the bottom sediments during summer based on $\delta^{18} \mathrm{O}$ measurements and an isotope fractionation model, whereas Murrell and Lehrter (2011) found that benthic respiration only contributes on average $20 \pm 4 \%$ of total respiration below the pycnocline. The relative contributions of benthic and water column respiration are strongly affected by the assumed depth of the bottom layer.

In order to better understand the relative importance of these processes, considerable efforts have been invested in modeling the DO dynamics and hypoxia within the system. These models range from relatively simple regression mod- els (Turner et al., 2005, 2006; Greene et al., 2009; Forrest et al., 2011; Feng et al., 2012) to more complex process simulations that emphasize either biogeochemical processes in simplified physical frameworks (Justić et al., 1996, 2002; Eldridge and Morse, 2008; Green et al., 2008) or physical circulation using detailed hydrographic models with simple parameterizations of biogeochemical process (Hetland and DiMarco, 2008; Lehrter et al., 2013). More recently a number of fully coupled physical-biogeochemical models have become available (Fennel et al., 2013; Laurent and Fennel, 2014; Feng et al., 2014; Justić and Wang, 2014).

Coupled models of DO dynamics and circulation have been used successfully in other coastal systems with seasonal hypoxia including Chesapeake Bay (i.e., Cerco and Cole, 1993; Cerco, 1995). More recently, Li et al. (2015) coupled an empirical DO model derived from observations with a high-resolution hydrodynamic model to derive a DO budget for Chesapeake Bay. An even simpler empirical DO parameterization was used by Scully (2013) to illustrate the important role of physical forcing in the formation of seasonal hypoxia. Both Li et al. (2015) and Scully (2013) obtained a realistic simulation of the seasonal cycle of DO and spatial distributions of hypoxic water.

Here we use a coupled physical-biogeochemical model for the LA shelf described in Fennel et al. $(2011,2013)$ that was recently extended to include phosphate by Laurent et al. (2012) and Laurent and Fennel (2014). The biogeochemical model explicitly simulates DO and is coupled to the realistic three-dimensional circulation model of Hetland and DiMarco (Hetland and DiMarco, 2008, 2012). Here we build upon the earlier work to identify the key processes controlling DO dynamics.

The paper is organized as follows. First we describe the coupled physical-biogeochemical model and its DO source and sink terms. Then we validate model-simulated DO and oxygen production and consumption rates against available observations. We explore spatial and temporal patterns of water column metabolism across the shelf and its interaction with air-sea fluxes. We also analyze the summer DO balance for different regions, which allows us to identify the key controlling processes and how they vary in space. Finally, we examine the role that sub-pycnocline primary production plays in hypoxia generation.

\section{Model description}

Our physical model is the Regional Ocean Modeling System (Haidvogel et al., 2008; ROMS, http://myroms.org) configured for the Mississippi-Atchafalaya outflow region as described in Hetland and DiMarco $(2008,2012)$. The model grid covers the Louisiana continental shelf with a horizontal resolution ranging from $\sim 20 \mathrm{~km}$ in the southwestern corner to $1 \mathrm{~km}$ near the Mississippi Delta, and has 20 terrainfollowing vertical layers with increased resolution near the 


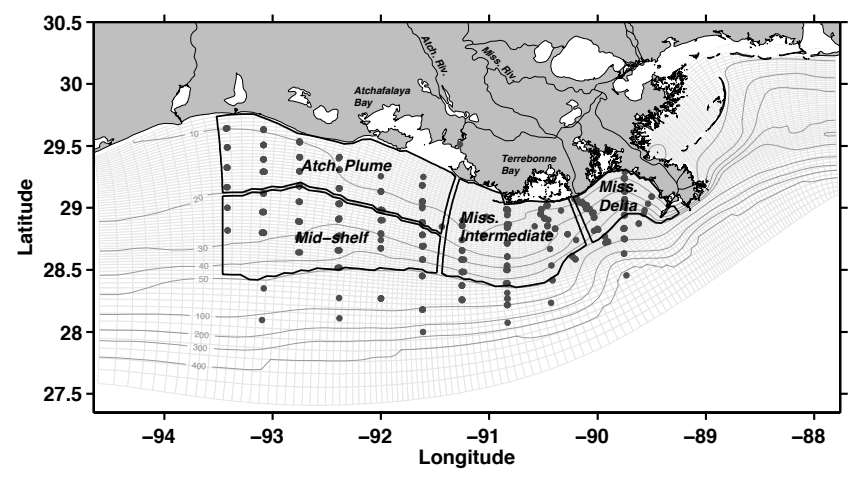

Figure 1. Model grid (light-grey lines) and bathymetry (in meters). The black lines delineate areas used during model analysis and are referred to as Mississippi Delta, Mississippi Intermediate, Atchafalaya Plume, and Mid-shelf region in the text. The black dots are stations where primary production (Lehrter et al., 2009) and respiration rates (Murrell et al., 2013) were collected.

surface and bottom (Fig. 1). The model uses a fourth-order horizontal advection scheme for tracers and a third-order upwind scheme for the advection term in the momentum equation. Vertical gradients are calculated with conservative parabolic splines, and vertical mixing is parameterized using the Mellor and Yamada (1982) turbulent closure scheme. An average profile of temperature and salinity, based on historical hydrographic data (Boyer et al., 2006) and assumed to be horizontally uniform, is used as the physical boundary condition. At the three open boundaries, gradient conditions are used for the free surface, radiation conditions for the three-dimensional velocities, and a Flather (1976) condition with no mean barotropic background flow for the twodimensional velocities. The model is forced with 3-hourly winds from the NCEP North American Regional Reanalysis (NARR) and climatological surface heat and freshwater fluxes from da Silva et al. (1994a, b). Freshwater inputs from the Mississippi and Atchafalaya rivers are based on daily measurements of transport by the US Army Corps of Engineers at Tarbert Landing and Simmesport, respectively.

The biological component of the model uses the nitrogen cycle model of Fennel et al. $(2011,2013)$ but was extended to include phosphate (Laurent et al., 2012) and river dissolved organic matter as additional state variables. The model is a relatively simple representation of the pelagic nitrogen $(\mathrm{N})$ cycle, including two species of dissolved inorganic $\mathrm{N}$, i.e., nitrate $\left(\mathrm{NO}_{3}\right)$ and ammonium $\left(\mathrm{NH}_{4}\right)$; phosphorus $\left(\mathrm{PO}_{4}\right)$; one phytoplankton group (Phy); chlorophyll (Chl) as a separate state variable to allow for photoacclimation; one zooplankton group (Zoo); two pools of detritus representing large, fast-sinking particles (LDet) and suspended, small particles (SDet); and river-borne dissolved organic matter (RDOM). Combined with the freshwater discharge described above, the model receives river nutrients $\left(\mathrm{NO}_{3}\right.$ and $\left.\mathrm{NH}_{4}\right)$ and organic matter based on the US Geological Survey (USGS) estimates

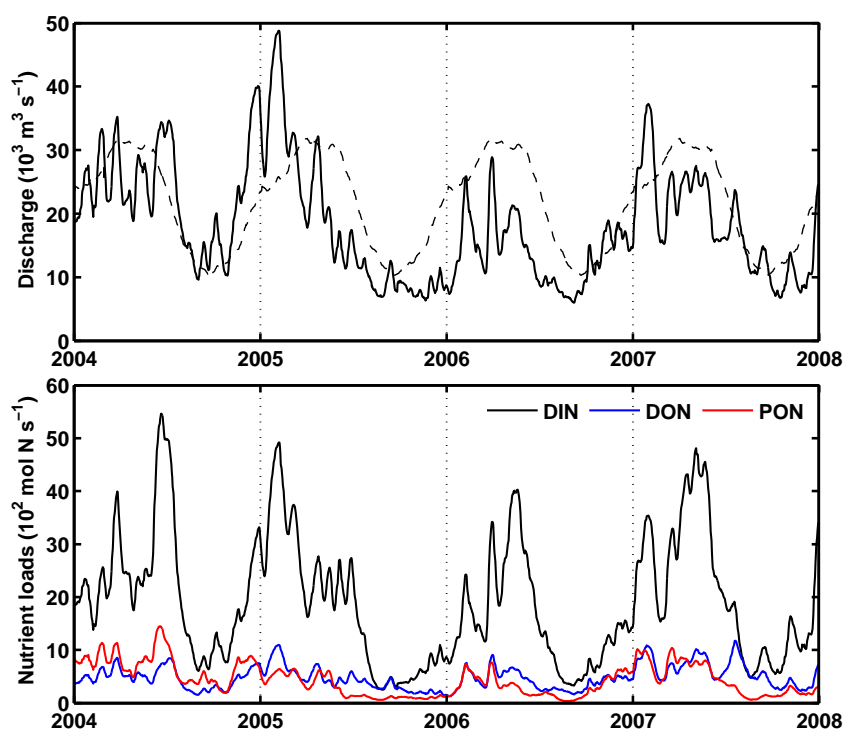

Figure 2. Mississippi and Atchafalaya River freshwater discharge (upper panel) and nutrient loads (lower panel) in 2004-2007. The dashed line indicates the long-term climatology (1983-2010).

(http://toxics.usgs.gov/). More specifically, river dissolved organic nitrogen (DON) was determined as the difference between filtered total Kjeldahl nitrogen (TKN) and $\mathrm{NH}_{4}$, and particulate organic nitrogen (PON) was defined as the difference between unfiltered and filtered TKN (Fig. 2). Different from our previously published simulations where river organic nitrogen enters the pool of SDet in the model without distinguishing between dissolved and particulate fractions, here river DON and PON enter the pools of RDOM and SDet, respectively. The only biological term in the equation for RDOM is remineralization to $\mathrm{NH}_{4}$ in the water column. We chose a remineralization rate of $0.03 \mathrm{~d}^{-1}$ for RDOM, an order of magnitude lower than that of small detritus $\left(0.3 \mathrm{~d}^{-1}\right)$ to reflect the observation that riverine dissolved organic matter is less labile than phytoplankton-derived organic matter (Shen et al., 2012). A schematic of the extended N cycle model is shown in Fig. 3. Also shown are the biological sources and sinks of DO, including photosynthetic production, nitrification, respiration in water column and sediment, and the air-sea flux of oxygen across the air-sea interface. At the open boundaries, $\mathrm{NO}_{3}, \mathrm{PO}_{4}$, and oxygen were prescribed using the NODC World Ocean Atlas. All other biological state variables at the boundary were set to small positive values. Model parameterization and previous validations were described in Fennel et al. (2006, 2011, 2013), Laurent et al. (2012), and Laurent and Fennel (2014). For the sake of completeness, all parameter values are given in Table S1 of the Supplement. 


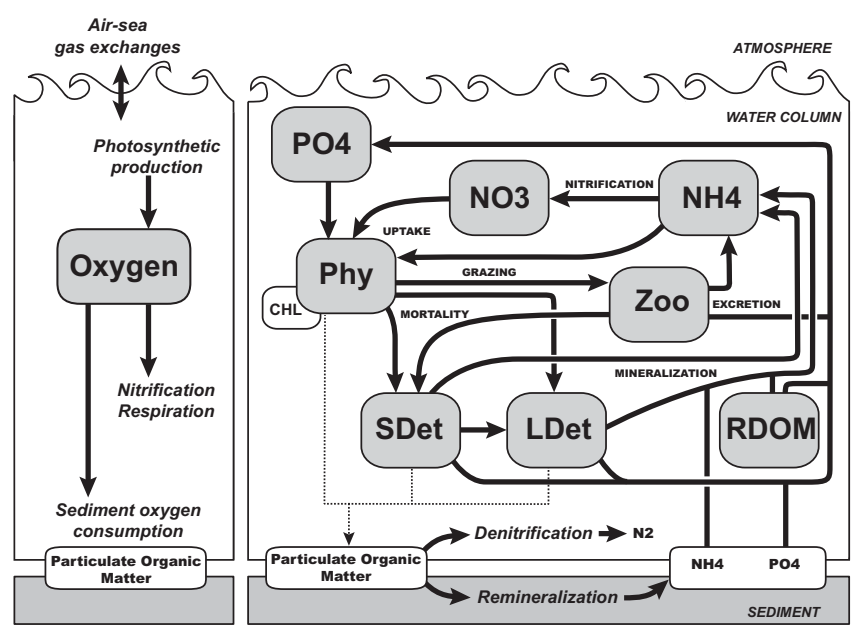

Figure 3. Schematic of the biological model.

The equation for the DO conservation is given by

$$
\begin{aligned}
& \frac{\partial \mathrm{DO}}{\partial t}=-\left(u \frac{\partial \mathrm{DO}}{\partial x}+v \frac{\partial \mathrm{DO}}{\partial y}+w \frac{\partial D O}{\partial z}\right) \\
& +\frac{\partial}{\partial z}\left(K_{v} \frac{\partial \mathrm{DO}}{\partial z}\right)+\mathrm{PP}+\mathrm{WR}+F_{\mathrm{bf}},
\end{aligned}
$$

where $x$ and $y$ represent the two horizontal coordinates and $z$ the vertical coordinate; $u, v$, and $w\left(\mathrm{~m} \mathrm{~s}^{-1}\right)$ represent velocity components in $x, y$, and $z$ coordinates, respectively; and $K_{\mathrm{v}}$ is the vertical diffusivity $\left(\mathrm{m} \mathrm{s}^{-2}\right)$. On the right-hand side of the Eq. (1), the first term represents horizontal and vertical advection of DO, and the second term is the vertical diffusion of DO (horizontal diffusivity $K_{\mathrm{H}}$ is set to 0 in the model and hence we neglected horizontal diffusion terms in Eq. 1). Here the advection and diffusion terms are computed using the advanced numerical schemes built into the ROMS hydrodynamic model. The term PP is the primary production and WR represents the sum of water column respiration and nitrification. Although not strictly accurate, the use of the terminology WR is consistent with the use of WR in the observational literature where measurements of water column oxygen consumption include the contribution of nitrification. The term $F_{\text {bf }}$ represents the boundary oxygen fluxes, namely the air-sea flux of oxygen at the top layer and the sediment oxygen consumption at the bottom layer, the parameterizations of which are detailed below.

Following Fennel et al. (2013), an air-sea flux of oxygen $\left(F_{\text {air-sea }}\right.$, in units of $\left.\mathrm{mmol} \mathrm{O}_{2} \mathrm{~m}^{-2} \mathrm{~d}^{-1}\right)$ is prescribed in the top layer of the model as

$F_{\text {air-sea }}=\frac{v k_{\mathrm{O}_{2}}}{\Delta z}\left(\mathrm{DO}_{\mathrm{sat}}-\mathrm{DO}\right)$,

where $\mathrm{DO}$ and $\mathrm{DO}_{\text {sat }}$ are the oxygen concentration and concentration at saturation, respectively; $\Delta z$ is the thickness of the respective grid box; and $v k_{\mathrm{O} 2}$ is the gas exchange coeffi-
Table 1. RMSE and bias (both in units of $\mathrm{mmol} \mathrm{O}_{2} \mathrm{~m}^{-3}$ ) between simulated and observed bottom DO concentrations. Comparisons were conducted over the simulation period from 2004 to 2007 using all available observations. Bias was calculated as model minus observation. $N$ is the number of observations available for each category.

\begin{tabular}{lrrrrrrr}
\hline & \multicolumn{2}{c}{ Model } & & \multicolumn{2}{c}{ Model+CCR } & \\
\cline { 2 - 3 } & RMSE & Bias & & RMSE & Bias & \multirow{2}{*}{$N$} \\
\hline Mississippi Delta & 74.6 & 43.3 & & 61.6 & 15.6 & 182 \\
Mississippi Intermediate & 72.2 & 40.3 & & 61.5 & 18.7 & 845 \\
Atchafalaya Plume & 66.3 & 35.0 & & 58.7 & 16.6 & 377 \\
Mid-shelf & 48.9 & 15.6 & & 54.0 & -18.8 & 435 \\
\hline All data & 66.4 & 33.7 & & 59.3 & 9.1 & 1839 \\
\hline
\end{tabular}

cient for oxygen based on Wanninkhof (1992), such that

$v k_{\mathrm{O}_{2}}=0.31 u_{10}^{2} \sqrt{\frac{660}{S c_{\mathrm{Ox}}}}$,

where $u_{10}$ is the wind speed at $10 \mathrm{~m}$ above the sea surface and $S c_{\mathrm{Ox}}$ is the Schmidt number, calculated as in Wanninkhof (1992).

The parameterization for sediment oxygen consumption (SOC) used in this study was developed by Hetland and DiMarco (2008) and based on observed sediment oxygen fluxes from Rowe et al. (2002). In this parameterization, SOC $\left(\mathrm{mmol} \mathrm{O}_{2} \mathrm{~m}^{-2} \mathrm{~d}^{-1}\right)$ linearly increases with increasing bottom-water oxygen $\left(\mathrm{DO}, \mathrm{mmol}_{2} \mathrm{~m}^{-3}\right.$ ) for concentrations lower than $50 \mathrm{mmol} \mathrm{O}_{2} \mathrm{~m}^{-3}$ and saturates when concentrations are higher than $100 \mathrm{mmol} \mathrm{O}_{2} \mathrm{~m}^{-3}$. Also, $\mathrm{SOC}$ is dependent on temperature $\left(T,{ }^{\circ} \mathrm{C}\right)$ such that it doubles for every $10^{\circ} \mathrm{C}$ temperature increase (i.e., $Q_{10}=2$ ). The equation is given as follows:

$$
\begin{aligned}
& \text { SOC }=6\left[\mathrm{mmolO}_{2} \mathrm{~m}^{-2} \mathrm{~d}^{-1}\right] \times 2^{T / 10^{\circ} \mathrm{C}} \\
& \times\left(1-\exp \left(-\frac{\mathrm{DO}}{30\left[\mathrm{mmolO}_{2} \mathrm{~m}^{-3}\right]}\right)\right) .
\end{aligned}
$$

In Fennel et al. (2013) this parameterization was extended to include an $\mathrm{NH}_{4}$ flux into the bottom water proportional to oxygen uptake by the sediments. Therefore, organic matter sinking out of the water column essentially leaves the system while empirically determined fluxes of oxygen into the sediments and ammonium out of the sediments are prescribed.

Motivated by the model-data comparisons, described below, we conducted a sensitivity experiment where a spatially and temporally constant oxygen consumption rate $\left(1.5 \mathrm{mmol} \mathrm{O}_{2} \mathrm{~m}^{-3} \mathrm{~d}^{-1}\right)$ was added to the water column oxygen pool (simulation denoted as "Model+CCR"). In order to distinguish between the role of biological processes in the water column (primary production and water column respiration, denoted as PP and WR, respectively) and the combination of physical transport and sediment respiration, we 


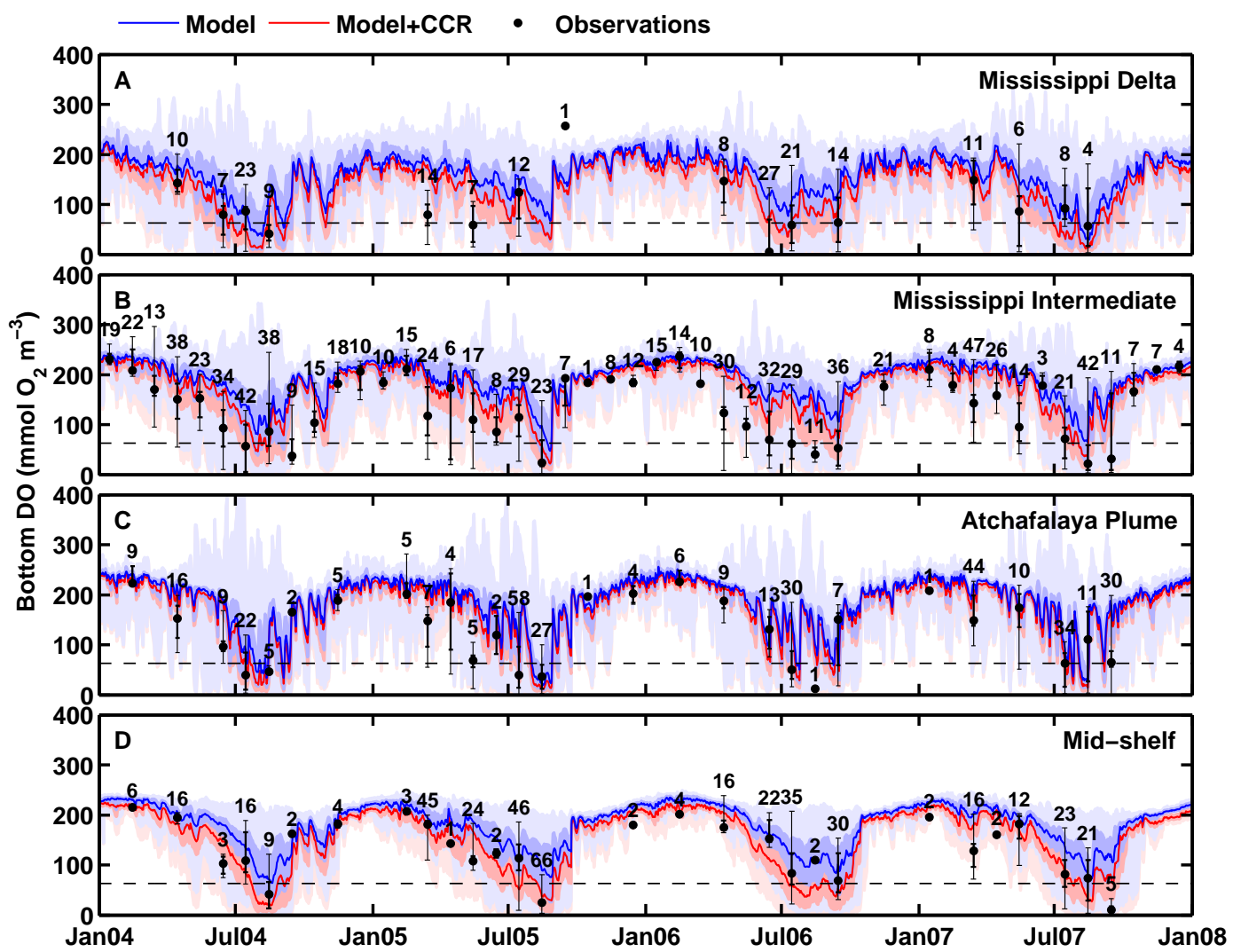

Figure 4. Time series of simulated and observed dissolved oxygen concentration (DO) in bottom water in the Mississippi Delta, Mississippi Intermediate, Atchafalaya Plume, and Mid-shelf regions. For the simulations, the medians are shown as solid lines (Model: blue line; Model+CCR: red line), the range between the 25th and 75th percentiles as dark-blue/red area, and the range between the minimum and maximum value as light-blue/red area. For the observations, the medians of monthly binned observations are shown as black dots, the range between the 25 th and 75 th percentiles as thick vertical lines, and the range between minimum and maximum values as thin vertical lines. The number of observations in each monthly bin is given above each maximum value. The dashed line indicates the hypoxia criterion of $62.5 \mathrm{mmol} \mathrm{O}_{2} \mathrm{~m}^{-3}$. Observations are from Rabalais et al. (2007), Lehrter et al. (2009, 2012), Nunnally et al. (2012), Murrell et al. (2014), and the $\mathrm{MCH}$ program.

conducted two further sensitivity experiments where all biological processes in the water column were turned off (denoted as "Model w/o PP and WR" and "Model+CCR w/o PP and WR" in comparison to the full model simulation and Model+CCR, respectively).

All simulations were run from 1 January 2004 to 31 December 2007. For model analysis we defined four geographical zones across the Louisiana continental shelf: three sub-regions associated with the Mississippi River plume (Mississippi Delta, Mississippi Intermediate, Mid-shelf), and another sub-region associated with the Atchafalaya River plume (Atchafalaya Plume) (Fig. 1). These four sub-regions cover most stations that comprise the observational data sets used for model validation: (1) DO concentrations from Rabalais et al. (2007), Nunally et al. (2013), Murrell et al. (2013b), and the Mechanisms Controlling Hypoxia $(\mathrm{MCH})$ program; (2) in situ measurements of water column respiration rates from 10 cruises during spring, summer, and fall from 2003 to 2007 (Murrell et al., 2013a); (3) the concurrent measurements of phytoplankton production from Lehrter et al. (2009); and (4) benthic flux measurements from Rowe et al. (2002), Murrell and Lehrter (2011), Lehrter et al. (2012), and McCarthy et al. (2013). Locations for the observed primary production and water column respiration rates are shown as black dots in Fig. 1.

\section{Results}

\subsection{Simulated oxygen dynamics and model validation}

Time series of simulated and observed bottom DO both show a seasonal cycle reaching a maximum between December and February and minimum between July and August (Fig. 4). In summer the median of simulated bottom DO is consistently larger than observations in the Mississippi Intermediate region, but otherwise observations and simulation agree well. Simulated bottom DO falls within the observed range of variability for all four regions. 
Table 2. RMSE and bias (both in units of $\mathrm{mmol} \mathrm{O}_{2} \mathrm{~m}^{-2} \mathrm{~d}^{-1}$ ) between simulated and observed primary production (PP) or water column respiration (WR). Comparisons were conducted over the simulation period from 2004 to 2007 using all available observations. Bias was calculated as model minus observations. $N$ is the number of observations for each category.

\begin{tabular}{|c|c|c|c|c|c|c|c|c|c|}
\hline & \multicolumn{4}{|c|}{$\mathrm{PP}$} & \multicolumn{4}{|c|}{ WR } & \multirow[b]{3}{*}{$N$} \\
\hline & \multicolumn{2}{|c|}{ Model } & \multicolumn{2}{|c|}{ Model+CCR } & \multicolumn{2}{|c|}{ Model } & \multicolumn{2}{|c|}{ Model+CCR } & \\
\hline & RMSE & Bias & RMSE & Bias & RMSE & Bias & RMSE & Bias & \\
\hline Miss. Delta & 145.2 & -42.3 & 145.5 & -43.6 & 115.8 & -49.4 & 104.4 & -17.9 & 55 \\
\hline Miss. Inter. & 94.7 & 10.5 & 95.0 & 9.2 & 93.3 & -45.9 & 84.5 & -19.4 & 60 \\
\hline Atch. Plume & 114.1 & 12.5 & 114.0 & 11.2 & 62.6 & -27.6 & 58.4 & -8.2 & 77 \\
\hline Mid-shelf & 91.8 & 50.2 & 91.1 & 48.4 & 75.8 & -7.0 & 81.7 & 35.6 & 71 \\
\hline All data & 112.0 & 10.8 & 112.0 & 9.3 & 86.5 & -30.8 & 81.9 & -1.0 & 263 \\
\hline
\end{tabular}

Table 3. RMSE and bias (both in units of $\mathrm{mmol} \mathrm{O}_{2} \mathrm{~m}^{-2} \mathrm{~d}^{-1}$ ) between simulated median of sediment oxygen consumption (SOC) and observed SOC. The simulation period ranged from 2004 to 2007, while observations from different sources were collected during longer period from 1991 to 2011. Bias was calculated as model median minus observation with same bottom dissolved oxygen (DO) concentration. $N$ is the number of observations available for each category.

\begin{tabular}{lrrrrrrr}
\hline & \multicolumn{2}{c}{ Model } & & \multicolumn{2}{c}{ Model+CCR } & \\
\cline { 2 - 3 } & RMSE & Bias & & RMSE & Bias & \multirow{2}{*}{$N$} \\
\hline Rowe et al. (2012) & 15.9 & 11.1 & & 13.6 & 8.0 & 12 \\
McCarthy et al. (2013) & 15.8 & 10.2 & & 13.9 & 7.0 & 18 \\
Lehrter et al. (2012) & 26.1 & 24.6 & & 22.4 & 20.7 & 22 \\
Murrell and Lehrter (2011) & 24.7 & 21.2 & & 21.7 & 18.1 & 31 \\
\hline All data & 22.3 & 18.2 & & 19.5 & 14.9 & 83 \\
\hline
\end{tabular}

We report model bias and root-mean-square error (RMSE) as statistical measures of agreement between simulated and observed bottom DO in Table 1. Bias was calculated as model minus observations; thus a positive bias indicates that the model overestimates the observations. Table 1 indicates that the model overestimates the observed bottom DO in all regions with an average bias of $33.7 \mathrm{mmol} \mathrm{O}_{2} \mathrm{~m}^{-3}$. Based on this comparison, the model performs best in the Mid-shelf region (bias of $15.6 \mathrm{mmol} \mathrm{O}_{2} \mathrm{~m}^{-3}$ ) and worst in the Mississippi Delta region (bias of $43.3 \mathrm{mmol} \mathrm{O}_{2} \mathrm{~m}^{-3}$ ).

Profiles of bias between simulated and observed DO profiles are shown in Fig. 5 for the summer months. Simulated DO often overestimates observed DO, but remains typically within one standard deviation of the observations except for the bottom layer (e.g., in June).

Observed and simulated rates of primary production (PP) and water column respiration (WR) are shown in Fig. 6, and statistical measures of model-data agreement are given in Table 2. The model simulates the observed PP reasonably well, but underestimates the WR observations, although the model is within one standard deviation of the observations (Fig. 6 and Table 2).
Simulated SOC within all four regions is plotted against bottom DO and compared with available observations in Fig. 7. Simulated SOC increases with increasing bottom DO for oxygen concentrations below $\sim 80 \mathrm{mmol} \mathrm{O}_{2} \mathrm{~m}^{-3}$ and declines thereafter because of the temperature effect (SOC halves for each temperature decrease of $10^{\circ} \mathrm{C}$ ). SOC observations from different sources vary over a large range from 0 to $40 \mathrm{mmol} \mathrm{O}_{2} \mathrm{~m}^{-2} \mathrm{~d}^{-1}$ (Fig. 7). Simulated SOC is at the upper range of the available observations. Model bias in Table 3 indicates that the median of simulated SOC overestimates the observed SOC when combining all sources (average bias $18.2 \mathrm{mmol} \mathrm{O}_{2} \mathrm{~m}^{-2} \mathrm{~d}^{-1}$ ).

\subsection{Validation of the Model+CCR simulation}

The model biases described in previous section (i.e., the underestimation of WR and overestimation of SOC) motivated us to carry out an additional simulation (Model+CCR) with increased WR. The additional, constant oxygen consumption rate $\left(1.5 \mathrm{mmol} \mathrm{O}_{2} \mathrm{~m}^{-3} \mathrm{~d}^{-1}\right)$ was determined from Table 2 (average bias of $30.8 \mathrm{mmol} \mathrm{O}_{2} \mathrm{~m}^{-2} \mathrm{~d}^{-1}$ divided by the average water column depth of $20.4 \mathrm{~m}$ ) and should compensate for the bias in model-simulated WR.

Compared with the previous model simulation, Model+CCR reduces the overall model-data discrepancy in WR (average bias of $-1.0 \mathrm{mmol} \mathrm{O}_{2} \mathrm{~m}^{-2} \mathrm{~d}^{-1}$ ) but overestimates the observed WR in the Mid-shelf region (bias of $35.6 \mathrm{mmol} \mathrm{O}_{2} \mathrm{~m}^{-2} \mathrm{~d}^{-1}$ ) (Fig. 6 and Table 2). The increased WR draws down the simulated DO concentrations, improving agreement between the observed and simulated bottom DO in all regions (average bias of $9.1 \mathrm{mmol} \mathrm{O}_{2} \mathrm{~m}^{-3}$ ) except the Mid-shelf region, where the observed bottom DO is significantly underestimated (bias of $-18.8 \mathrm{mmol} \mathrm{O}_{2} \mathrm{~m}^{-3}$ ) (Fig. 4 and Table 1). Compared to the previous simulation, the reduced DO concentrations throughout the water column in Model+CCR generally improve the model performance with lower biases, except for the Mid-shelf region in June and July (Fig. 5). The reduced bottom DO concentrations in Model+CCR also lead to a reduction in the simulated 

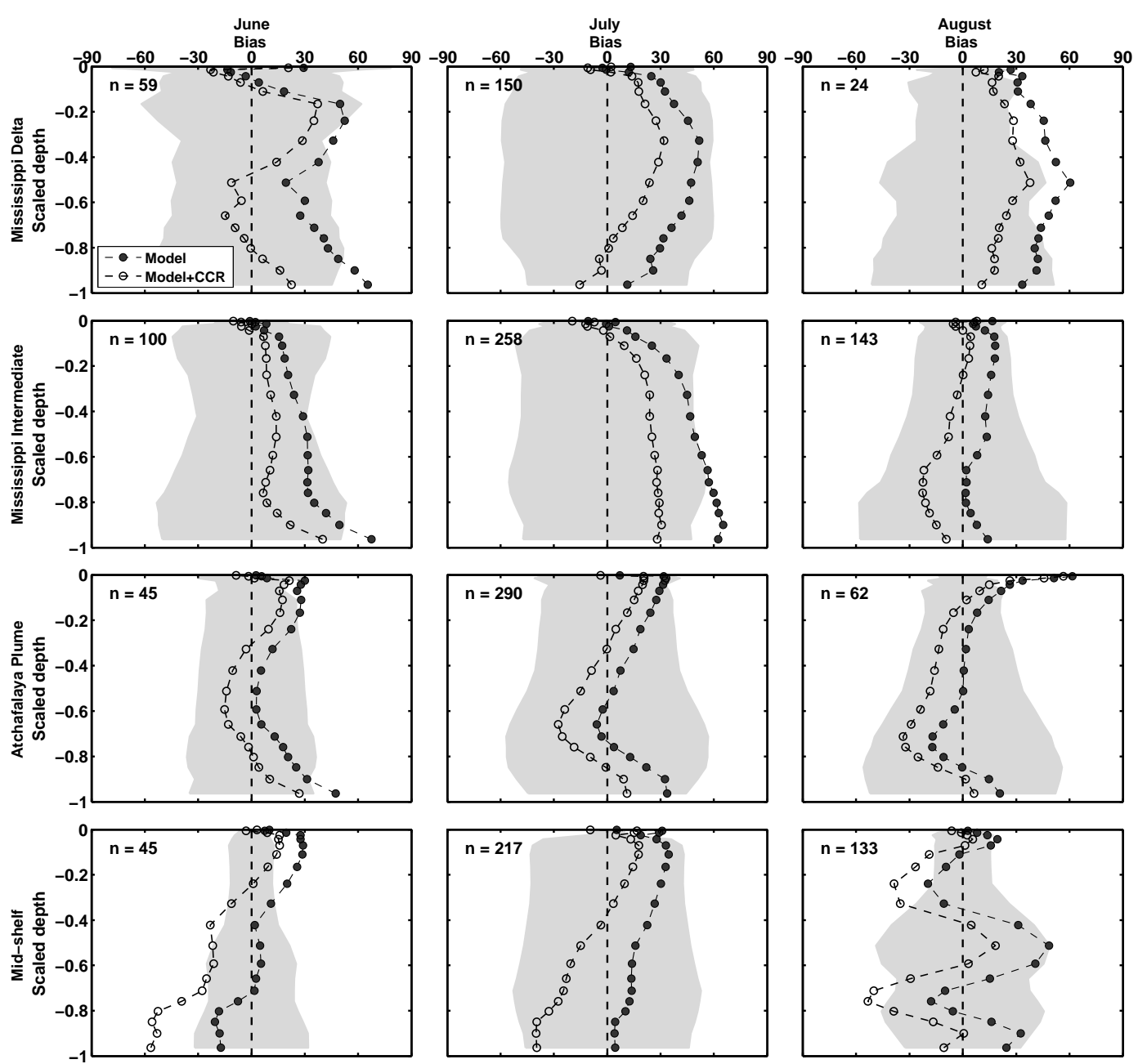

Figure 5. Vertical profiles of model bias (model minus observations, $\mathrm{mmol} \mathrm{O}_{2} \mathrm{~m}^{-3}$ ) in dissolved oxygen (DO) calculated from 2004 to 2007 for June to August in the four sub-regions. The vertical axis is the scaled depth, where 0 corresponds to the surface and -1 to the bottom. The light-grey areas represent the standard deviation in the observations. Observations are from Rabalais et al. (2007), Lehrter et al. (2009, 2012), Murrell et al. (2014), and the MCH program.

SOC (as SOC is dependent on bottom DO) and thereby slightly improve the agreement between simulated and observed SOC with lower RMSE and bias (average bias of $14.9 \mathrm{mmol} \mathrm{O}_{2} \mathrm{~m}^{-2} \mathrm{~d}^{-1}$ ) (Fig. 7 and Table 3).

\subsection{Oxygen balance}

In this section, we evaluate the DO balance for the summer period (June to August) for different regions of the LA shelf to identify the key processes controlling hypoxia. We focus the detailed analysis on the model simulation without additional WR; results from Model+CCR will be discussed at the end of the section. For simplicity, we are considering oxygen consumption due to nitrification to be included in the respiration term, and not as a separate process for deriving the oxygen balance. Though we are referring to the sum of respiration and nitrification as WR, we recognize that nitrification is a chemoautotrophic process. While not strictly accurate, this is consistent with the use of WR in the observational literature where measurements of water column oxygen consumption include the contribution of nitrification.

We first explore the simulated seasonal and spatial patterns in water column metabolism across the shelf and its interaction with the air-sea flux of oxygen (Fig. 8). The Mississippi Delta and Atchafalaya Plume regions, which are directly impacted by the river, transit from autotrophy in June and July to heterotrophy for the rest of the year. The Mississippi Intermediate and Mid-shelf regions, however, are heterotrophic throughout the year. In terms of air-sea exchange, oxygen is outgassing during summer and taken up during the rest of the year in all sub-regions, corresponding to the seasonal pattern in water column metabolism (more heterotrophic in winter and less heterotrophic or autotrophic in summer) and the seasonal cycle of surface water temperatures, which affect 


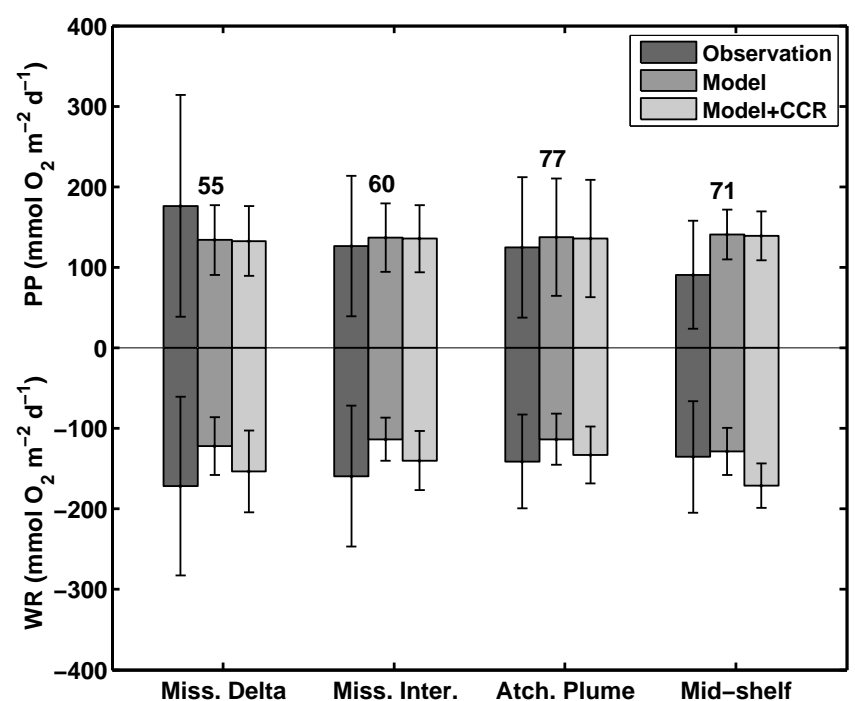

Figure 6. Vertically integrated rates of observed and simulated primary production (upper panel) and water column respiration (lower panel) in the four sub-regions. The error bars indicate the standard deviation. The number of observations in each sub-region is given above the error bars.

oxygen solubility contributing to outgassing in summer and uptake in winter. The oxygen flux into the ocean increases with the degree of heterotrophy, demonstrating the important role of air-sea gas exchange in replenishing DO in the water column.

When considering an oxygen balance for the water column, it is useful to distinguish distinct vertical layers. We considered the following three layers in our analysis of the summer oxygen balance: a surface layer above the main pycnocline, a mid-layer extending from the main pycnocline to $5 \mathrm{~m}$ above the sediment, and a $5 \mathrm{~m}$ thick bottom layer above the sediment (i.e., the layer where hypoxia occurs most frequently, as demonstrated in Fig. 6 in Fennel et al., 2013). We defined the pycnocline as the depth of maximum BruntVaisala frequency (Pond and Pickard, 1983) and restricted our analysis to horizontal grid cells where all three layers existed (i.e., a main pycnocline was present and was more than $5 \mathrm{~m}$ above the bottom). We then integrated the terms in Eq. (1) vertically over each layer at each desired grid cell on each desired day. The advection and diffusion terms were evaluated as divergences, namely fluxes of DO into or out of the given volume through advection or diffusion. Finally, we averaged the integrated results over all grid cells within a selected sub-region and over June to August in order to obtain the summer oxygen balance for the sub-regions.

Figure 9 shows the summer oxygen balance in the three layers and four sub-regions (numbers are provided in Table S2 of the Supplement). The surface layers in all four sub-regions are autotrophic, while the bottom layers are heterotrophic (Fig. 9). In the surface layer, biochemical processes (PP and WR) far exceed physical transport of oxygen.

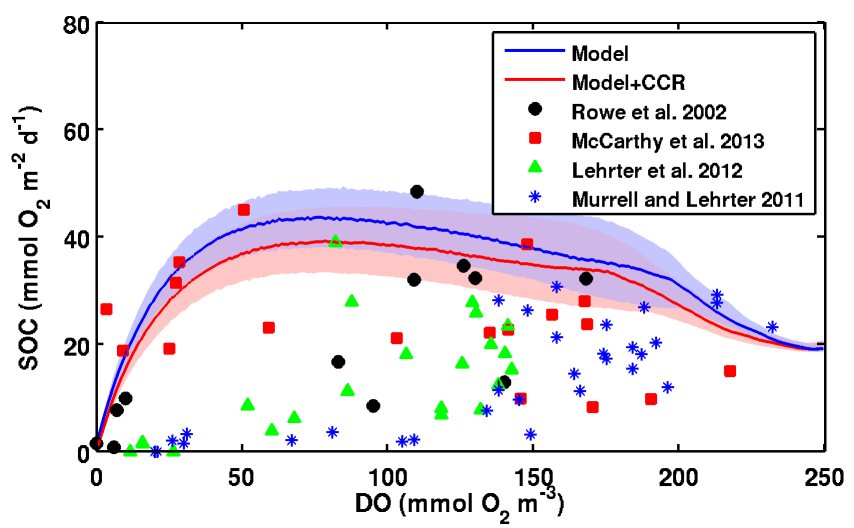

Figure 7. Model-simulated sediment oxygen consumption (SOC) versus bottom dissolved oxygen (DO) for the period 2004 to 2007, including the median (solid line) and the range between 25 th and 75 th percentiles (shaded area). Also shown for comparison are observations from Rowe et al. (2002), McCarthy (2013), Lehrter et al. (2012), and Murrell and Lehrter (2011).

Table 4. Shelf-wide average observed and simulated percentage of primary production below the pycnocline (mean \pm standard deviation). $N$ is the number of observations.

\begin{tabular}{lcll}
\hline Cruise & $N$ & \multicolumn{2}{c}{$\begin{array}{c}\text { Percentage of PP below } \\
\text { pycnocline (\%) }\end{array}$} \\
\cline { 3 - 4 } & & Observation & Simulation \\
\hline Mar 2005 & 24 & $23.3 \pm 29.4$ & $27.8 \pm 26.9$ \\
Apr 2006 & 31 & $35.3 \pm 30.0$ & $23.4 \pm 25.2$ \\
Jun 2006 & 54 & $29.3 \pm 25.7$ & $18.6 \pm 19.2$ \\
Sep 2006 & 71 & $38.7 \pm 25.7$ & $39.4 \pm 28.2$ \\
May 2007 & 64 & $25.8 \pm 25.0$ & $36.2 \pm 29.6$ \\
Aug 2007 & 60 & $24.7 \pm 23.3$ & $40.9 \pm 30.9$ \\
RMSE & & & 42.5 \\
Bias & & & 2.8 \\
$\mathrm{~N}$ & & & 304 \\
\hline
\end{tabular}

The positive net community production and decreasing oxygen solubility associated with the increasing water temperature in summer lead to oxygen outgassing to the atmosphere and net transport of oxygen downward to deeper waters.

The mid-layer is autotrophic in all four sub-regions as well, with an average PP of $48 \%$ occurring below the pycnocline and $38 \%$ in the mid-layer. About $10 \%$ of PP occurs within the $5 \mathrm{~m}$ bottom layer, where hypoxia occurs most frequently (Fig. 9). We compared the simulation results with observations from Lehrter et al. (2009), as a percentage of production below the pycnocline for each cruise (Table 4). Considering the rather large observed standard deviations, the percentages of sub-pycnocline PP in the simulations (18.6$40.9 \%$ ) agree well with observations (23.3-38.7\%).

On average the sub-pycnocline PP offsets $68 \%$ of total respiration below the pycnocline and $27 \%$ of total respira- 

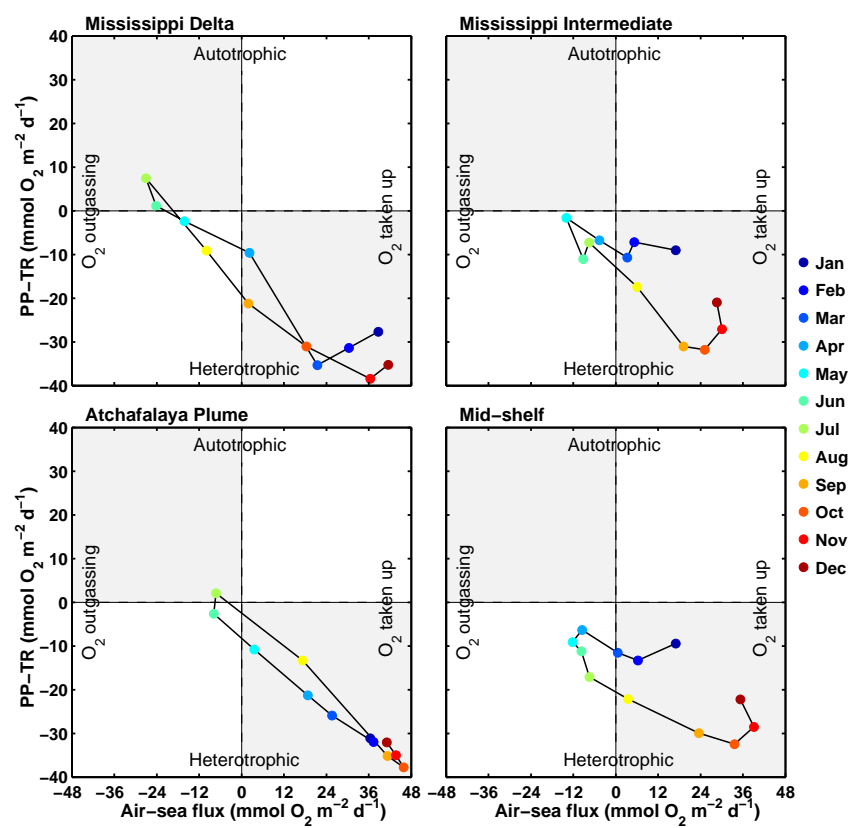

Figure 8. Simulated net community production (PP-TR) versus airsea flux of oxygen for the four sub-regions. The colored dots represent monthly means averaged over 2004-2007. Positive air-sea flux indicates oxygen is taken by water, whereas negative air-sea flux indicates oxygen outgasses. Positive PP-TR suggests autotrophic, whereas negative PP-TR suggests heterotrophic. Standard deviations of the air-sea flux in different months and sub-regions range widely from 13 to $58 \mathrm{mmol} \mathrm{O}_{2} \mathrm{~m}^{-2} \mathrm{~d}^{-1}$ and standard deviation of PP-TR range from 12 to $63 \mathrm{mmol} \mathrm{O}_{2} \mathrm{~m}^{-2} \mathrm{~d}^{-1}$, both of which are higher in Mississippi Delta and Atchafalaya Plume and lower in the other two regions.

tion within the $5 \mathrm{~m}$ bottom layer (Fig. 9). The percentages are higher in 2006 (a drought year), when PP offsets $72 \%$ of total respiration below the pycnocline and $31 \%$ of total respiration within the bottom $5 \mathrm{~m}$.

The $5 \mathrm{~m}$ bottom layer is heterotrophic in all sub-regions, with SOC representing the single largest oxygen flux (Fig. 9). SOC accounts for $36 \%$ of total respiratory oxygen demand below the pycnocline when averaged over the shelf and summer months. The fraction of SOC rises to $68 \%$ when limited to the bottom $5 \mathrm{~m}$ (Fig. 9). Driven by the strong vertical DO gradient in the water column, vertical diffusion is the primary mode of DO replenishment for the bottom layer, offsetting on average $32 \%$ of total respiration over the shelf. Advection, driven by the typical summer upwelling circulation on the LA shelf, is another important DO source for bottom waters offsetting on average $29 \%$ of total respiration shelf-wide.

Adding WR in the Model+CCR simulation impacted the summer oxygen balance by making the water column more heterotrophic and decreasing the relative contributions of SOC and WR to total respiration (Table S3 and Fig. S3 in Supplement). In Model+CCR the mid-layers in all subregions and all three layers in Mid-shelf region become het- erotrophic in summer months. Also, the simulated fraction of SOC to total respiration averaged over the four sub-regions during summer decreases from 36 to $26 \%$ within belowpycnocline water layer and from 68 to $57 \%$ within the bottom $5 \mathrm{~m}$ layer.

\subsection{Role of sub-pycnocline PP in hypoxia generation}

Time series of simulated hypoxic area from the sensitivity run without biological processes in the water column (Model w/o PP and WR) are shown in comparison to the full model and the observed hypoxic extent in Fig. 10. The temporal evolution of hypoxic area is almost identical in both simulations, with "Model w/o PP and WR" simulating an only slightly larger hypoxic area in summer. A similar pattern is observed for simulated hypoxic volume (Fig. S1) and for the simulations with the additional oxygen sink (Fig. S4).

\section{Discussion}

\subsection{Simulated oxygen dynamics and model validation}

Overall, the model simulates the evolution of oxygen and the magnitudes and spatial distribution of PP well, but it tends to overestimate bottom DO and underestimate WR (within one standard deviation of observations). One possible explanation is that the model does not receive any dissolved or particulate organic matter inputs from estuarine sources other than the Mississippi and Atchafalaya rivers. Several recent studies (Bianchi et al., 2010, Murrell et al., 2013a; Fry et al., 2015) have suggested that the inshore coastal waters represent a source of oxygen-consuming organic matter that may be episodically transported onto the LA shelf.

The model also overestimates the observed SOC from all sources, especially those observed by Lehrter et al. (2012) and Murrell and Lehrter (2011) (Fig. 7, Table 3). Using the same model as in this study, Fennel et al. (2013) showed that generation of hypoxia on the LA shelf is very sensitive to the parameterization of SOC, primarily because the hypoxic conditions on the shelf are restricted to a relatively thin layer above the sediment. Fennel et al. (2013) further showed that the SOC parameterization based on observations from Rowe et al. (2002), which is used in this study, performed best in simulating the observed hypoxic extent, whereas parameterization based on lower SOC values from Murrell and Lehrter (2011) led to almost no hypoxia in this model. The apparent discrepancy between SOC observations and parameterizations used in mechanistic models remains to be reconciled. One explanation could be that empirical SOC measurements underestimate the true oxygen demand, because they do not account for accumulation of reduced metabolites of anaerobic metabolism (e.g., $\mathrm{NH}_{4}^{+}, \mathrm{HS}^{-}, \mathrm{Fe}^{2+}$ ). Accumulation of anaerobic metabolites can be episodically important in scavenging oxygen, thus acting to maintain hypoxic conditions during periods when traditional SOC measurements 


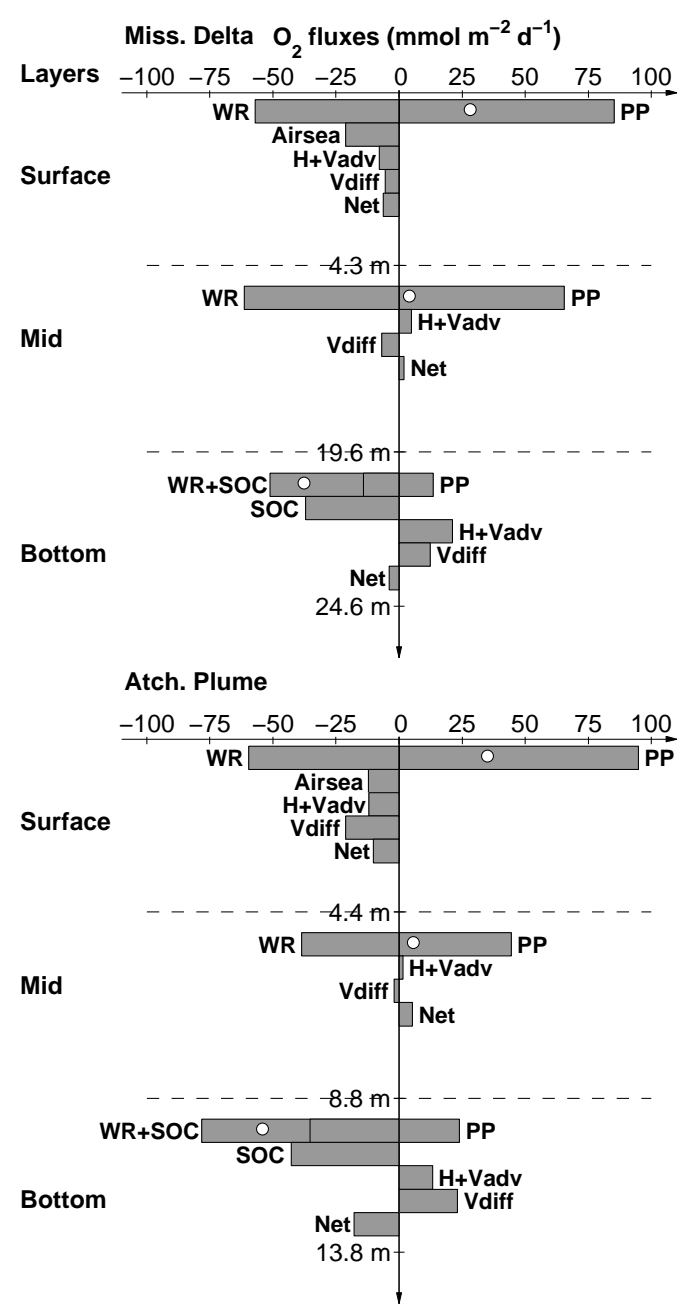

Miss. Inter. $\mathrm{O}_{2}$ fluxes $\left(\mathrm{mmol} \mathrm{m} \mathbf{~}^{-2} \mathrm{~d}^{-1}\right)$
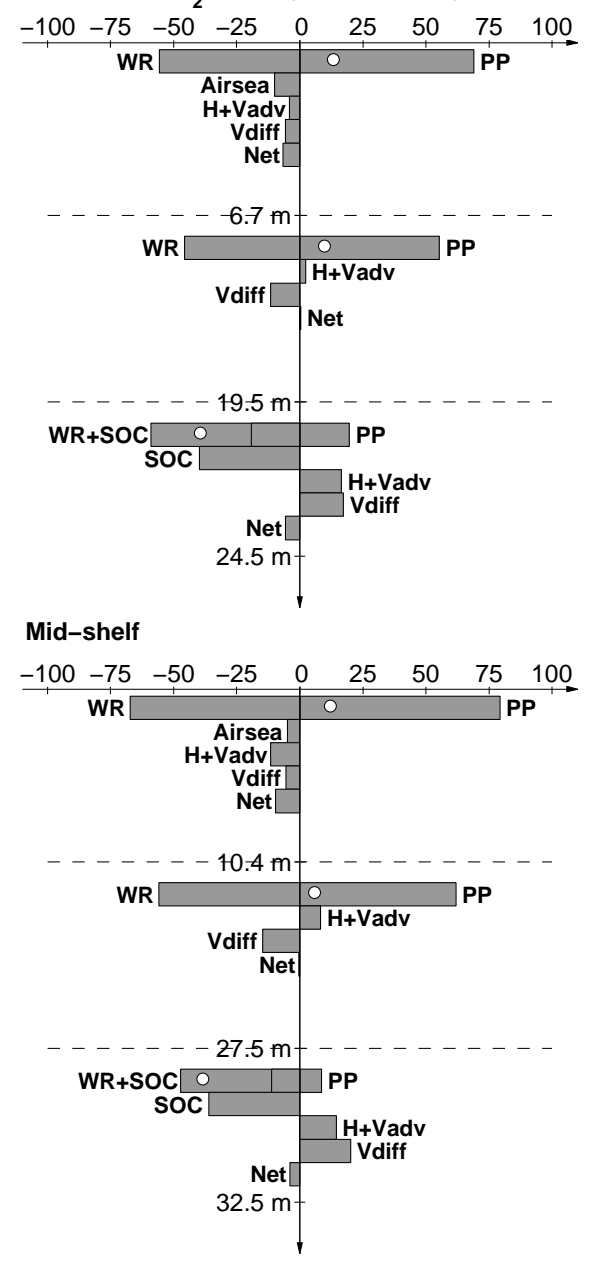

Figure 9. Simulated 4-year (2004-2007) mean oxygen balance in summer for the four sub-regions. Oxygen source and sink terms are given for the surface layer above the pycnocline, for the mid-layer, and for the $5 \mathrm{~m}$ thick bottom layer. The average depth of the pycnocline, depth at $5 \mathrm{~m}$ above bottom, and the average water column depth are indicated for each sub-region. The open circles indicate the balance of primary production (PP) and respiration + nitrification (WR) in each layer. For the bottom layer, the bars for respiration + nitrification (WR) and sediment oxygen consumption (SOC) are shown stacked and SOC is repeated separately. The net rate of oxygen change in each layer (i.e., the sum of all oxygen source and sink terms) is given and denoted as Net.

suggest a small DO sink. This interpretation is supported by Lehrter et al. (2012), who found that DIC fluxes (a better measure of total oxygen demand) were relatively constant and insensitive to overlying DO concentration. Another explanation could be that the thickness of the simulated bottom boundary layer is overestimated. If this is the case, SOC would have to be larger than in reality in order to produce hypoxic bottom water. Future work on validating the expression and dynamics of the bottom boundary layer and its effect on hypoxia dynamics will address this question.

The SOC parameterization has the inherent limitation that it does not account for spatial variability in the supply of particulate organic matter reaching the sediment. An alternative model where SOC varies as a response to the amount of organic matter sinking to the sediment (Fennel et al.,
2011, 2013) essentially simulated identical results as presented here. While the SOC parameterization used here is simple, it does include two key parameters known to modulate SOC: temperature and dissolved oxygen.

In order to assess the effects of the model biases in WR, we conducted a sensitivity experiment where an additional, constant oxygen consumption rate was applied to the water column DO based on observed WR rates from Murrell et al. (2013a). This generally improves the comparisons among measured and simulated WR, bottom-water DO, and SOC, except in the Mid-shelf region, where WR is overestimated and bottom DO is underestimated. The increased WR and slightly decreased SOC in the Model+CCR simulation also reduce the SOC fraction of total respiratory oxygen demand. 

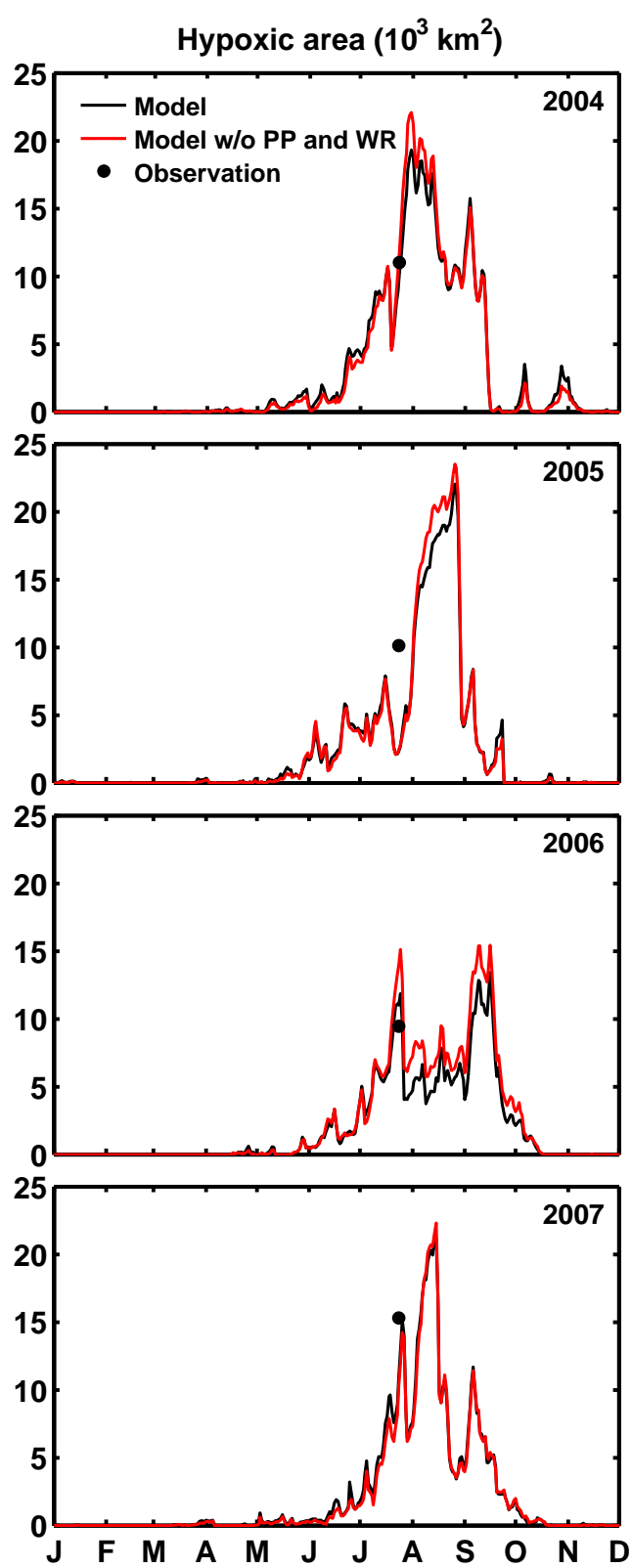

Figure 10. Time series of simulated hypoxic extent for the full model (black line) and the model without biological processes in the water column (red line). Also shown is the observed hypoxic extent in late July (black dots). The observed hypoxic extent was estimated by linearly interpolating the observed oxygen concentrations onto the model grid and then calculating the area with oxygen concentrations below the hypoxic threshold (Fennel et al., 2013).

\subsection{Primary processes controlling oxygen dynamics}

The simulated seasonal transition from autotrophy to heterotrophy in the Mississippi Delta and Atchafalaya Plume regions has previously been reported in mesohaline waters (salinity: 15-29) in the Mississippi River plume (Breed et al., 2004). The Mississippi Intermediate and Mid-shelf re- gions were heterotrophic throughout the year, implying a net import of organic carbon. This result is consistent with the observations of Murrell et al. (2013a), who found net heterotrophy on the western shelf and in deeper waters of the LA shelf. A more recent study by Fry et al. (2015) also suggested that the autotrophic near-river and nearshore areas could be net source regions of carbon fueling hypoxia in adjacent midshelf waters.

Despite the heterotrophy, the main sink for oxygen is outgassing in the Mississippi Intermediate and Mid-shelf regions during the summer hypoxic season. This result is consistent with frequent observations of supersaturated DO concentrations in surface plume waters, particularly in the Louisiana Bight region (Murrell et al., 2013b). The simultaneous occurrence of heterotrophy and outgassing of oxygen is primarily due to density stratification of the water column, which isolates the autotrophic upper waters that actively exchange oxygen with the atmosphere from the heterotrophic waters below. As shown in the summer DO balance (Fig. 9), the surface layers above the pycnocline were autotrophic in all sub-regions, driving outgassing of oxygen to the atmosphere despite the whole water column being heterotrophic. The decreased oxygen solubility of warmer waters typical of summer conditions also promotes outgassing, but the effect is relatively small compared to the autotrophy in surface waters (oxygen gas exchange is fast and the summer change in water temperature is relatively small on the LA shelf). We have carried out sensitivity experiments where we doubled and halved the air-sea gas exchange coefficient (results not presented in the paper) and found that the model results are insensitive to the air-sea gas exchange rates, likely because the air-sea oxygen flux is fast.

It has previously been demonstrated, based on observations, that a strong near-surface pycnocline is a prerequisite for hypoxia on the LA shelf, while a weaker, near-bottom pycnocline determines the hypoxic layer that actually forms (Wiseman et al., 1997). This was confirmed by model simulations (Fennel et al., 2013), which show that hypoxia is constrained to a thin layer above the sediment over large parts of the shelf. A more recent retrospective analysis of data collected during shelf-wide sampling cruises reported that the 27-year (1985-2011) average thickness of the bottom hypoxic layer is $3.9 \mathrm{~m}$ and that there was an increasing trend in hypoxic layer thickness from 1985 to 2011 (Obenour et al., 2013).

Consistent with observations by Lehrter et al. (2009), our model demonstrated that a large fraction of PP occurred below the pycnocline and even within bottom $5 \mathrm{~m}$ water (Fig. 9, Table 4). This is presumably because the euphotic zone extends well below the pycnocline and sometimes to the bottom on the LA shelf (Chen et al., 2000; Lehrter et al., 2009). Lehrter et al. (2009) also observed that the euphotic zone in non-plume areas (salinity $>31$ ) is deeper than in plume areas, and that the average shelf-wide light attenuation strongly correlates with freshwater discharge from the 
Mississippi and Atchafalaya rivers. In agreement with these observations, the simulated percentage of sub-pycnocline PP is higher in the Mississippi Intermediate region (52\% below the pycnocline and $13.6 \%$ in the $5 \mathrm{~m}$ bottom layer) than in the Mississippi Delta region (48 and $8.3 \%$, respectively), and higher throughout the shelf in 2006 (a drought year with low freshwater discharge) than on average over the 4 years simulated (52\% compared to $48 \%$ ).

The importance of physical transport in replenishing bottom-water DO pools has been found in other coastal systems with seasonal hypoxia, including Chesapeake Bay, where Kemp et al. (1992) estimated that in summer the vertical oxygen flux across the pycnocline and the net longitudinal oxygen exchange offset $\sim 55$ and $\sim 38 \%$ of total respiration below the pycnocline, respectively. More recent modeling work by $\mathrm{Li}$ et al. (2015) estimated that vertical diffusion and net advective fluxes respectively offset $\sim 27$ and $\sim 64 \%$ of total respiration in the bottom $10 \mathrm{~m}$ during summer. Kemp et al. (1992) also showed that increased biological consumption of DO in bottom waters of Chesapeake Bay increases horizontal and vertical DO gradients and thereby increases physical transport of DO to the bottom waters during March to July. On the LA shelf the occasional occurrence of tropical storms and hurricanes can rapidly erode stratification and replenish bottom waters with DO. The lateral advection of oxygenated water from adjacent deep basins during upwellingfavorable wind conditions can also increase bottom-water DO on the LA shelf (Rabalais et al., 2007).

The result that SOC is the dominant oxygen sink in waters directly overlying the sediments (within $5 \mathrm{~m}$ above the bottom) is consistent with previous observational estimates for the LA shelf. Quinones-Rivera et al. (2007) estimated that SOC accounts for $\sim 73 \%$ of the total DO loss within $1 \mathrm{~m}$ of the sediments during summer based on $\delta^{18} \mathrm{O}$ measurements and an isotope fractionation model. Since the isotope approach only provides relative fractions of sediment and water column respiration, we cannot directly compare SOC and WR from Quinones-Rivera et al. (2007) to our simulations. However, the simulated proportions of sediment respiration to total respiration (on average $36 \%$ below pycnocline and $68 \%$ in the $5 \mathrm{~m}$ bottom layer) are consistent with the estimates of Quinones-Rivera et al. (2007). Adding the additional DO sink decreased the proportions of SOC to total respiration $(26 \%$ below the pycnocline and $57 \%$ in the $5 \mathrm{~m}$ bottom layer) but did not change the model result that SOC is the dominant DO sink in the bottom $5 \mathrm{~m}$, demonstrating the relative sensitivity of the model to the SOC parameterization used.

\subsection{Role of sub-pycnocline PP in hypoxia generation}

The summer oxygen balance presented in the previous section suggests that physical transport processes and sediment respiration are major drivers of oxygen dynamics on the LA shelf, and that PP below the pycnocline may mitigate hy- poxic conditions. However, in a sensitivity experiment where we disabled all biological processes in the water column, the spatial extent of hypoxic bottom waters is only slightly reduced, suggesting that PP below the pycnocline has only a minor effect on hypoxia.

\section{Summary and conclusions}

In this study we used a physical-biogeochemical model to investigate the dynamics of dissolved oxygen and hypoxia on the LA shelf and to identify the key controlling processes. Comparisons with observations demonstrate that the model simulates the evolution of oxygen well but tends to overestimate bottom DO and SOC, and underestimates WR. When a constant oxygen consumption rate is added in the water column to correct the bias in WR rates, the model-simulated oxygen dynamics agree better with observations in all subregions except the Mid-shelf. This result suggests that organic matter from inshore waters may need to be included in future versions of the model.

Consistent with observations of Murrell et al. (2013a), our model demonstrated that the LA shelf is essentially heterotrophic throughout the year except for the areas directly impacted by rivers during June and July. This implies a net import of organic carbon on the LA shelf. Air-sea gas exchange was the primary mode of replenishing the very heterotrophic waters in non-summer months with relatively strong mixing. However, in summer, stratification isolates the autotrophic surface from the heterotrophic lower waters. In the Mississippi Intermediate and Mid-shelf regions this isolation results in significant outgassing of oxygen across the air-sea interface despite a heterotrophic water column, exacerbating the risk of hypoxia in these regions.

In summer, the model indicates that a substantial fraction of primary production $(\sim 48 \%)$ occurs below the pycnocline and about $10 \%$ of primary production occurs within $5 \mathrm{~m}$ of the bottom, where hypoxia forms most frequently. In a sensitivity experiment where biological processes in the water column (i.e., PP and WR) were turned off, we demonstrate that the below-pycnocline PP mitigates hypoxia only slightly, and that physical processes and sediment oxygen consumption together largely determine the spatial extent and dynamics of hypoxia on the LA shelf.

\section{The Supplement related to this article is available online at doi:10.5194/bg-12-2063-2015-supplement.}

Acknowledgements. This work was supported through NOAA CSCOR grants NA06NOS4780198 and the US IOOS Coastal Ocean Modeling Testbed. NOAA NGOMEX publication no. 202.

Edited by: M. Grégoire 


\section{References}

Bianchi, T. S., DiMarco, S. F., Cowan Jr., J. H., Hetland, R. D., Chapman, P., Day, J. W., and Allison, M. A.: The science of hypoxia in the Northern Gulf of Mexico: A review, Sci. Total Environ., 408, 1471-1484, 2010.

Bierman, V. J., Hinz, S. C., Zhu, D. W., Wiseman, W. J. Jr., Rabalais, N. N., and Turner, R. E.: Preliminary mass balance model of primary productivity and dissolved oxygen in the Mississippi River plume/inner gulf shelf region, Estuar., 17, 886-899, 1994.

Boyer, T. P., Antonov, J. I., Garcia, H. E., Johnson, D. R., Locarnini, R. A., Mishonov, A. V., Pitcher, M. T., Baranova, O. K., and Smolyar, I. V.: World Ocean Database 2005, edited by: Levitus, S., NOAA Atlas NESDIS 60, US Government Printing Office, Washington, DC, DVDs, 190 pp., 2006

Breed, G. A., Jackson, G. A., and Richardson T. L.: Sedimentation, carbon export and food web structure in the Mississippi River plume described by inverse analysis, Mar. Ecol. Prog. Ser., 278, 35-51, 2004.

Cerco, C. F.: Response of Chesapeake Bay to nutrient load reductions, J. Environ. Eng., 121, 549-557, 1995.

Cerco, C. F. and Cole, T. M.: Three-dimensional eutrophication model of Chesapeake Bay, J. Environ. Eng., 119, 1006-1025, 1993.

Chen, X., Lohrenz, S. E., and Wiesenburg, D. A.: Distribution and controlling mechanisms of primary production on the LouisianaTexas continental shelf, J. Mar. Syst., 25, 179-207, 2000.

Cho, K., Reid, R. O., and Nowlin, W. D.: Objectively mapped stream function fields on the Texas-Louisiana shelf based on 32 months of moored current meter data, J. Geophys. Res., 103, 10377-10390, 1998.

Cochrane, J. D. and Kelly, F. J.: Low-frequency circulation on the Texas-Louisiana continental shelf, J. Geophys. Res., 91, 1064510659, 1986.

da Silva, A. M., Young-Molling, C. C., and Levitus, S.: Atlas of Surface Marine Data 1994 Vol. 3, Anomalies of fluxes of heat and momentum. NOAA Atlas NESDIS 8, Natl. Oceanic and Atmos. Admin., Silver Spring, MD, 1994a.

da Silva, A. M., Young-Molling, C. C., and Levitus, S.: Atlas of Surface Marine Data 1994 Vol. 4, Anomalies of fresh water fluxes, NOAA Atlas NESDIS 9, Natl. Oceanic and Atmos. Admin., Silver Spring, MD, 1994b.

Eldridge, P. M. and Morse, J. W.: Origins and temporal scales of hypoxia on the Louisiana shelf: Importance of benthic and subpycnocline water metabolism. Mar. Chem., 108, 159-171, 2008.

Eldridge, P. M. and Roelke, D. L.: Origins and scales of hypoxia on the Louisiana shelf: importance of seasonal plankton dynamics and river nutrients and discharge. Ecol. Model., 221, 1028-1042, 2010.

Feng, Y., DiMarco, S. F., and Jackson, G. A.: Relative role of wind forcing and riverine nutrient input on the extent of hypoxia in the northern Gulf of Mexico, Geophys. Res. Lett., 39, L09601, doi:10.1029/2012GL051192, 2012.

Feng, Y., Fennel, K., Jackson, G. A., DiMarco, S. F., and Hetland, R. D.: A model study of the response of hypoxia to upwellingfavorable wind on the northern Gulf of Mexico shelf, J. Mar. Syst., 131, 63-73, 2014.

Fennel, K., Wilkin, J., Levin, J., Moisan, J., O’Reilly, J., and Haidvogel, D.: Nitrogen cycling in the Middle Atlantic Bight: results from a three-dimensional model and implications for the North
Atlantic nitrogen budget, Global Biogeochem. Cy., 20, GB3007, doi:10.1029/2005GB002456, 2006.

Fennel, K., Hetland, R., Feng, Y., and DiMarco, S.: A coupled physical-biological model of the Northern Gulf of Mexico shelf: model description, validation and analysis of phytoplankton variability, Biogeosciences, 8, 1881-1899, doi:10.5194/bg-8-18812011, 2011.

Fennel, K., Hu, J., Laurent, A., Marta-Almeida, M., and Hetland, R. D.: Sensitivity of hypoxia predictions for the Northern Gulf of Mexico to sediment oxygen consumption and model nesting, J. Geophys. Res., 118, 990-1002, 2013.

Flather, R. A.: A tidal model of the northwest European continental shelf, Memoires de la Societe Royale de Sciences de Liege, 141164, 1976.

Forrest, D., Hetland, R. D., and DiMarco, S.: Multivariable statistical regression models of the areal extent of hypoxia over the Texas-Louisiana continental shelf, Environ. Res. Lett., 6, 1-10, 2011.

Fry, B., Justicé, D., Riekenberg, P., Swenson, E., Turner, R. E., Wang, L., Pride, L., Rabalais, N. N., Kurtz, J. C., Lehrter, J. C., Murrell, M. C., Shadwick, E. H., and Boyd, B.: Carbon dynamics on the Louisiana continental shelf and cross-shelf feeding of hypoxia, Estuar. Coast., 38, 703-721, doi:10.1007/s12237-0149863-9, 2015.

Green, R. E., Breed, G. A., Dagg, M. J., and Lohrenz, S. E.: Modeling the response of primary production and sedimentation to variable nitrate loading in the Mississippi River plume, Cont. Shelf Res., 28, 1451-1465, 2008.

Greene, R. M., Lehrter, J., and Hagy, J.: Multiple regression models for hindcasting and forecasting midsummer hypoxia in the Gulf of Mexico, Ecol. Appl., 19, 1161-1175, 2009.

Haidvogel, D. B., Arango, H., Budgell, W. P., Cornuelle, B. D., Curchitser, E., Di Lorenzo, E., Fennel, K., Geyer, W. R., Hermann, A. J., Lanerolle, L., Levin, J., McWilliams, J. C., Miller, A. J., Moore, A. M., Powell, T. M., Shchepetkin, A. F., Sherwood, C. R., Signell, R. P., Warner, J. C., and Wilkin, J.: Ocean forecasting in terrain-following coordinates: formulation and skill assessment of the regional ocean modeling system, J. Comput. Phys., 227, 3595-3624, 2008.

Hetland, R. D. and DiMarco, S. F.: How does the character of oxygen demand control the structure of hypoxia on the TexasLouisiana continental shelf?, J. Mar. Syst., 70, 49-62, 2008.

Hetland, R. D. and DiMarco, S. F.: Skill assessment of a hydrodynamic model of circulation over the Texas- Louisiana continental shelf, Ocean Modell., 43/44, 64-76, 2012.

Justić, D., Rabalais, N. N., and Turner, R. E.: Effects of climate change on hypoxia in coastal waters: a doubled $\mathrm{CO}_{2}$ scenario for the northern Gulf of Mexico. Limnol. Oceanogr., 41, 992-1003, 1996.

Justić, D., Rabalais, N. N., and Turner, R. E.: Modeling the impacts of decadal changes in riverine nutrient fluxes on coastal eutrophication near the Mississippi River delta, Ecol. Model., 152, 33-46, 2002.

Justić, D. and Wang, L.: Assessing temporal and spatial variability of hypoxia over the inner Louisiana-upper Texas shelf: Application of an unstructured-grid three-dimensional coupled hydrodynamic-water quality model, Cont. Shelf Res., 72, 163179, 2014. 
Kemp, W. M., Sampou, P. A., Garber, J., Tuttle, J., and Boynton, W. R.: Seasonal depletion of oxygen from bottom waters of Chesapeake Bay: Roles of benthic and planktonic respiration and physical exchange processes, Mar. Ecol.-Prog. Ser., 85, 137$152,1992$.

Laurent, A., Fennel, K., Hu, J., and Hetland, R.: Simulating the effects of phosphorus limitation in the Mississippi and Atchafalaya River plumes, Biogeosciences, 9, 4707-4723, doi:10.5194/bg-94707-2012, 2012.

Laurent, A. and Fennel, K.: Simulated reduction of hypoxia in the northern Gulf of Mexico due to phosphorus limitation, Elementa, 2, 000022, doi:doi:10.12952/journal.elementa, 2014.

Lehrter, J. C., Murrell, M. C., and Kurtz, J. C.: Interactions between Mississippi River inputs, light, and phytoplankton biomass and phytoplankton production on the Louisiana continental shelf, Cont. Shelf Res., 29, 1861-1872, 2009.

Lehrter, J. C., Beddick, D. L., Devereux, R., Yates, D. F., and Murrell, M. C.: Sediment-water fluxes of dissolved inorganic carbon, $\mathrm{O}_{2}$, nutrients, and $\mathrm{N}_{2}$ from the hypoxic region of the Louisiana continental shelf, Biogeochemistry, 109, 233-252, 2012.

Lehrter, J. C., Ko, D. S., Murrell, M. C., Hagy, J. D., Schaeffer, B. A., Greene, R. M., Gould, R. W., and Penta, B.: Nutrient distributions, transports, and budgets on the inner margin of a river-dominated continental shelf, J. Geophys. Res.-Oceans, 118, 4822-4838, 2013.

Lehrter, J. C., Fry, B., and Murrell, M. C.: Microphytobenthos production potential and contribution to bottom layer oxygen dynamics on the inner Louisiana continential shelf, Bull. Mar. Sci., 90, 765-780, 2014.

Li, Y., Li, M., and Kemp, M.: A budget analysis of bottomwater dissolved oxygen in Chesapeake Bay, Estuar. Coast, doi:10.1007/s12237-014-9928-9, 2015.

McCarthy, M. J., Carini, S. A., Liu, Z., Ostrom, N. E., and Gardner, W. S.: Oxygen consumption in the water column and sediments of the northern Gulf of Mexico hypoxic zone., Estuar. Coast. Shelf. Sci., 123, 46-53, 2013.

Mellor, G. L. and Yamada, T.: Development of a turbulence closure model for geophysical fluid problems. Rev. Geophys. Space Phys., 20, 851-875, 1982.

Murrell, M. C. and Lehrter, J. C.: Sediment and lower water column oxygen consumption in the seasonally hypoxic region of the Louisiana continental shelf, Estuar. Coast., 34, 912-924, 2011.

Murrell, M. C., Stanley, R. S., and Lehrter, J. C.: Plankton community respiration, net ecosystem metabolism, and oxygen dynamics on the Louisana continental shelf: implications for hypoxia, Cont. Shelf Res., 52, 27-38, 2013 a.

Murrell, M. C., Beddick, D. L., Devereux, R., Greene, R. M., Hagy, J. D., Jarvis, B. M., Kurtz, J. C., Lehrter, J. C., and Yates, D. F.: Gulf of Mexico hypoxia research program data report: 20022007, US Environmental Protection Agency, Washington, DC, EPA/600/R-13/257, http://tinyurl.com/ko9wj7j, p. 217, 2013b

Nunnally, C. C., Rowe, G. T., Thornton, D. C. O., and Quigg, A.: Sediment oxygen consumption and nutrient regeneration in the Northern Gulf of Mexico Hypoxic Zone, J. Coast. Res., 63, 8496, 2013.
Obenour, D. R., Scavia, D., Rabalais, N. N., Turner, R. E., and Michalak, A. M.: Retrospective analysis of midsummer hypoxic area and volume in the Northern Gulf of Mexico, 1985-2011, Environ. Sci. Technol., 47, 9808-9815, 2013.

Pond, S. and Pickard, G. L.: Introductory dynamical oceanography, 2nd edition Pergamon Press, Oxford, 1983.

Quinones-Rivera, Z. J., Wissel, B., Justic, D., and Fry, B.: Partitioning oxygen sources and sinks in a stratified, eutrophic coastal ecosystem using stable oxygen isotopes, Mar. Ecol. Prog. Ser., 342, 69-83, 2007.

Quinones-Rivera, Z. J., Wissel, B., Rabalais, N. N, and Justic, D.: Effects of biological and physical factors on seasonal oxygen dynamics in a stratified, eutrophic coastal ecosystem, Limnol. Oceanogr., 55, 289-304, 2010.

Rabalais, N. N., Turner, R. E., and Wiseman, W. J.: Gulf of Mexico hypoxia, a.k.a. "The Dead Zone", Ann. Rev. Ecol. Syst., 33, 235 263, 2002.

Rabalais, N. N., Turner, R. E., Sen Gupta, B. K., Boesch, D. F., Chapman, P., and Murrell, M. C.: Hypoxia in the northern Gulf of Mexico: Does the science support the plan to reduce, mitigate, and control hypoxia?, Estuar. Coast., 30, 753-772, 2007.

Rowe, G. T. and Chapman, P.: Continental shelf hypoxia: some nagging questions, Gulf of Mexico Sci., 20, 153-160, 2002.

Rowe, G. T., Kaeki, M. E. C., Morse, J. W., Boland, G. S., and Briones, E.G.E.: Sediment community metabolism associated with continental shelf hypoxia, northern Gulf of Mexico, Estuar., 25, 1097-1106, 2002.

Scully, M. E.: Physical controls on hypoxia in Chesapeake Bay: A numerical modeling study, J. Geophys. Res., 118, 1239-1256, 2013.

Shen, Y., Fichot, C. G., and Benner, R.: Floodplain influence on dissolved organic matter composition and export from the Mississippi-Atchafalaya River system to the Gulf of Mexico, Limnol. Oceanogr., 57, 1149-1160, 2012.

Testa, J. M. and Kemp, W. M.: Oxygen - Dynamics and Biogeochemical Consequences, in: Treatise on Estuarine and Coastal Science, edited by: Wolanski, E. and McLusky, D. S., Waltham, Academic Press, 2011.

Turner, R., Rabalais, N., Swenson, E., Kasprzak, M., and Romaire, T.: Summer hypoxia in the Northern Gulf of Mexico and its prediction from 1978 to 1995, Mar. Environ. Res., 59, 65-77, 2005.

Turner, R. E., Rabalais, N. N., and Justic, D.: Predicting summer hypoxia in the northern Gulf of Mexico: Riverine N, P, and Si loading, Mar. Pollut. Bull., 52, 139-148, 2006.

Wanninkhof, R.: Relationship between wind speed and gas exchange, J. Geophys. Res., 97, 7373-7382, 1992.

Wiseman, W., Rabalais, N., Turner, R., Dinnel, S., and MacNaughton, A.: Seasonal and interannual variability within the Louisiana coastal current: stratification and hypoxia, J. Mar. Syst., 12, 237-248, 1997. 